\title{
Research on the Reform and Practice of Ocean Electrical Engineering Course Based on Internet + Deep Learning
}

\author{
Ying Li \\ Tianjin Maritime College \\ Tianjin, 300350, China
}

\begin{abstract}
The purpose of this paper is to reform the marine electrical course with deep learning. This paper conducts analysis on Internet + education, deep learning concepts, new requirements for ship electrical courses, and marine training program 2016 ship electrical standards. According to the standard, the marine's electrical classroom teaching design and diagnosis and reform, curriculum evaluation pre-class, in-class, after-school development are combined to explore the multievaluation path and program. The knowledge construction, problem solving, student identity construction, and high-level thinking and innovative thinking of students in the ship electrical course are beneficial. Internet technology and teaching media resources are used to improve teaching behavior according to student learning effects, and teaching implementation strategies are refined, thus innovative education and traditional education are integrated and developed.
\end{abstract}

Keywords-Internet +; Deep learning; Marine electrical; Curriculum reform

\section{INTRODUCTION}

Deep learning is an understanding of learning. Learners can criticize new ideas and facts, and integrate them into the original cognitive structure. They can connect with many ideas and can transfer existing knowledge to new ones. In the context of the situation, and to make decision-making and problemsolving learning, for teachers to use deep learning to guide the design of the theme cut-in, the guide design of the new knowledge construction, the guide design of difficult breakthroughs, the guiding design of thinking improvement. Using the contradiction between the knowledge points of the teaching materials and the existing knowledge and experience of the students, the students are guided to reorganize relevant knowledge and experience,[1] and to infiltrate some basic thinking methods and strategies for solving problems. Teachers should, on the basis of fully respecting the status of students, correct their roles, closely follow the teaching objectives, and guide students to actively participate in learning activities.

As a product of new technological innovations, the Internet has provided a path for entrepreneurship in the booming development of various industries. In 2015, Ma Yun proposed at the World Internet Conference that the first industrial revolution took 50 years, the second industrial revolution took 50 years, and the Internet as the third technological revolution was less than 20 years. Facing the future "Internet" environment,[1] the deep integration of entrepreneurship education and professional education, whether it is entrepreneurs or employed people, should adapt to the development needs of the times from the perspective of thinking and career orientation, and build a curriculum system that adapts to the development of the times. The rise of deep learning in China in recent years is definitely not groundless, but has profound social motivations, theoretical basis and practical significance [2]. More specifically, the rise of deep learning in China is not only an objective requirement for the development of the information society, but also a natural product for learning scientific development, or an inevitable choice for the reform of curriculum teaching. First, deep learning is an objective requirement for the development of the information society [3]. The information society has unprecedented requirements for individual learning ability, practical ability, innovation ability and social responsibility. The learning method of simply focusing on knowledge memory and knowledge acquisition is far from adapting to the information society. Development of requirement. In fact, the emergence of deep learning in the West has been closely linked to this social development requirement from the beginning Throughout the value appeal of Western deep learning theory, deep learning is to let students reach the "four learning",[4] learn knowledge construction, learn problem solving, learn identity construction and learn high-order thinking. It is the key ability and essential character to adapt students to the requirements of the development of the information society. Deep learning is learning to learn social adaptation. Second, deep learning is a natural product of learning science development. Deep learning is a natural product of the development of human learning science to the third stage. From the essence of thought, contemporary learning science has carried out a complete disorder of the interaction between theory and practice, that is, practice precedes theory, and theory is not superior to practice. The theory and practice are equal and symbiotic, [5] breaking the traditional learning concept of learning and using, learning and separation. Based on this, contemporary learning science pays special attention to the learning problem in the natural situation, paying special attention to the learner's situational cognition and paying special attention to learning. Participation in the practice. Therefore, deep learning is the learning of participation in situational cognition. The third deep learning is an inevitable choice for curriculum reform [6]. Core literacy has become the basic direction and central guidance for primary and secondary schools and higher vocational education. At present, the 
question we have to consider and study is how to use core literacy and how to develop. According to conventional understanding, core literacy is the ability of students to develop their own abilities and adapt to their own social needs. From the perspective of knowledge learning, we theoretically advocate that knowledge is power and knowledge is productivity. However, in reality many students learn knowledge and cannot gain strength from knowledge. The reason for this phenomenon is that students do not have a solid knowledge of learning, and they are not exhaustive in their knowledge and cannot apply what they have learned. The classroom only pays attention to the teaching of knowledge and ignores practice and deeper learning. Therefore, deep learning also requires the development of deep knowledge building. The understanding of deep learning is also the result of deep learning of knowledge and deep understanding of knowledge. Deep learning is also diversified, gaining a deep understanding of knowledge through extensive reading, extensive practice, exchange of ideas, resource integration, and so on." Based on new technologies, new ideas and new requirements, it is urgent and research value to develop the teaching practice of marine electrical courses, and keep pace with the times to carry out teaching reform and practice.

\section{SEAFARERS TRAINING PROGRAM 2016 PAIRS OF MARINE ELECTRICAL STANDARDS}

In order to standardize the training of seafarers' crews and improve the quality of crew training, the Maritime Safety Administration of the Ministry of Transport prepared the "Sea" in accordance with the revised International Convention on the Standards of Training, Certification and Watch keeping for Seafarers of 1978 and the Regulations of the People's Republic of China on Seafarers. Seafarers Training Outline (2016 Rules), electrical requirements for ships are mainly reflected in the reading of electrical and simple electronic drawings, the structure and operation of electrical test and measurement equipment, electrical system equipment, switchboards, motors, generators and DC Maintenance and repair of gas systems and equipment, and operational safety requirements for marine electrical systems, including the safety isolation of electrical equipment required before personnel are allowed to overhaul the equipment, the detection of electrical faults and fault locations, and measures to prevent damage. Formulate theoretical and practical skills requirements based on competencies, and monitor implementation based on evaluation criteria. Requirements are shown in Table 1.

TABLE I MARINE ELECTRICAL COMPETENCY REQUIREMENTS

\begin{tabular}{|c|c|c|}
\hline Competency requirements & Theoretical knowledge requirements & Practical skill requirements \\
\hline $\begin{array}{c}\text { Reading of electrical and simple } \\
\text { electronic diagrams }\end{array}$ & $\begin{array}{c}\text { Circuit diagram and simple electronic } \\
\text { circuit diagram }\end{array}$ & $\begin{array}{c}\text { Circuit diagram and simple electronic } \\
\text { circuit diagram }\end{array}$ \\
\hline $\begin{array}{c}\text { Structure and operation of electrical } \\
\text { test and measurement equipment }\end{array}$ & $\begin{array}{c}\text { Structure and operation of electrical } \\
\text { testing equipment }\end{array}$ & $\begin{array}{c}\text { Skilled in measuring the insulation } \\
\text { resistance of electrical equipment using } \\
\text { a portable megohmmeter }\end{array}$ \\
\hline $\begin{array}{c}\text { Maintenance and repair of electrical } \\
\text { system equipment, switchboards, } \\
\text { motors, generators Detection of } \\
\text { electrical faults and fault locations } \\
\text { and measures to prevent damage }\end{array}$ & $\begin{array}{c}\text { Maintenance principle, generator, motor, } \\
\text { starter, power distribution system, DC } \\
\text { power system and equipment, Electrical } \\
\text { system fault diagnosis and protection, fault } \\
\text { protection, fault location }\end{array}$ & $\begin{array}{c}\text { Maintenance and repair, electric motor, } \\
\text { power distribution system Electrical } \\
\text { system fault diagnosis and protection, } \\
\text { fault protection, fault location }\end{array}$ \\
\hline
\end{tabular}

\section{A. The main theoretical knowledge}

Mainly master theoretical knowledge: circuit diagrams and simple electronic circuit diagrams. Familiar with the symbols and functions of the main electrical and electronic components used in the circuit diagram; familiar with the current flow and circuit diagram functions of the electronic/electrical components in the simple circuit diagram; familiar with different electrical diagrams, including block diagrams, system diagrams, circuit diagrams, wiring diagrams, etc.; Simple circuit diagram and drawing method of circuit diagram. The structure and operation of electrical testing equipment. Familiar with the function and working principle of insulation tester, continuity tester, multimeter and clamp ammeter; proficient in the use of insulation tester, continuity tester, multimeter and clamp ammeter. Maintenance and repair including maintenance principles, understanding the meaning of maintenance, understanding the meaning of fault repair, planned maintenance and condition monitoring, grasping the safety and isolation measures that must be taken before maintenance of the generator; familiar with the common faults of the generator and necessary Remedial measures; master the test method of generator insulation resistance value; familiar with routine maintenance and test methods of generators. Master the routine maintenance methods of the main circuit breakers; master the detection and corrective actions of the circuit breaker faults. Master the disassembly maintenance method of the motor; master the cause of the insulation failure and the method of checking the insulation resistance of the three-phase asynchronous motor; master the common faults and troubleshooting methods of the three-phase asynchronous motor. Master the disassembly maintenance method of the starter; master the common faults and troubleshooting methods of the starter. Familiar with the routine maintenance methods of transformers; familiar with the meaning of open circuit, grounding and short circuit; master the conditions of grounding faults, potential hazards and their impact on the power distribution system; master the method of using ground fault lamps and insulation testers to judge ground faults; Routine maintenance and testing methods for marine lighting equipment; understanding the manifestation of grounding faults in high-voltage electrical systems with neutral grounding. Master the cutting and end treatment methods and connections of cables; master the measurement of cable resistance, the method of temporarily repairing cable insulation and its limitations. Master the methods for periodic testing of 
emergency lighting equipment and standby power lines of ship propulsion devices; be familiar with battery maintenance and safety precautions to be taken; understand the effects of gases released by lead-acid batteries on electrolytes and improve methods; The meaning of the specific gravity of the electrolyte. Familiar with the cause of electric shock and the size of lethal current; familiar with the range of safe voltage; familiar with the safety measures necessary to work on electrical equipment in actual work; familiar with the isolation procedures required for electrical equipment; familiar with the safety and safety that must be taken before starting work Isolation precautions; familiar with the purpose of installing circuit breakers for interlocking devices; understanding the hazards associated with the space near the busbars; understanding the potential hazards and safe working procedures of the voltage/current transformer circuits used in the instrument; familiarizing with the combined power distribution cabinet doors Safety devices that are normally configured; familiar with safety and emergency procedures documented in the ship's safety management system. Familiar with the meaning of fault protection and the components of fault protection equipment; familiar with the commonly used overcurrent protection relay and its working principle; familiar with the type and characteristics of the fuse, master the replacement operation steps; familiar with the overload trip mechanism; The purpose and implementation of pressure and reverse power protection; familiar with the structure of the main switchboard and the functions of its main components; understanding the power supply method and grounding of the switchboard instrument; understanding the power supply method of the status indicator; grasping the danger of the space near the busbar, the potential danger of the instrument voltage / current transformer circuit and safe working procedures; master the common faults of small circuit breakers and their handling procedures; master the adjustment, maintenance and testing methods of common fault protection equipment. Understand the characteristics of pneumatic, hydraulic and electrical control systems; be familiar with simple control loops; be familiar with analog and digital equipment;) master the method of locating faults in a simple control system; master the safety precautions during fault location; Routine measures to prevent electrical equipment failure, including circuit burnout, poor contact, damage to the limit/micro switch, and failure

\section{B. The main practical skills}

The main mastery of practical skills mainly includes circuit diagrams and simple electronic circuit diagrams. Proficiency in the use of multimeters to measure resistance and AC, DC voltage. Diode performance measurement and polarity discrimination, transistor performance measurement and polarity discrimination, thyristor performance measurement and polarity discrimination, skilled use of clamp-type ammeter to measure line current, skilled use of $\mathrm{AC}$ voltmeter and ammeter. Skilled in disassembling AC motors, skilled in assembling AC motors, skilled in cleaning motors, inspecting parts, adding bearing greases; skilled in handling motors with damp and reduced winding insulation values; proficient in judging and eliminating common faults in three-phase asynchronous motors, including failure to start and start After the rotation speed is low and appears to be weak, the temperature rise is too high, the vibration during operation is too large, the bearing is overheated. Proficiency in the installation and maintenance of fluorescent lamps; proficient in judging and eliminating common faults of incandescent lamps, including: the bulb does not emit light, the bulb is strong, the light is dim or dim or light, the fuse is blown continuously, the light is dark red, etc. Proficiency in judging and eliminating the common faults of fluorescent lamps, including: the lamp does not emit light, the two ends of the lamp are not bright, the glare is difficult, the light is flickering or there is a spiral rolling band in the tube, and the ballast is abnormal. Proficiency test, adjust the set value and amplitude difference of pressure relay (or temperature relay); skilled to set time relay and thermal relay. Power outage accidents of automated power stations; Power grid jumps occur when conventional power plants are operated in parallel; power units of conventional power stations are jumped due to mechanical faults; conventional power plants run out of power during stand-alone operation; operating units of conventional power plants are protected by generator shortcircuit or loss of voltage Jumping. Proficiency in judging and eliminating the closing fault, false trip and tripping fault of the automatic air circuit breaker. Proficiency in the external short circuit, overload and loss (under) pressure faults of the generator. Maintenance of relays and contactors and tuning of their parameters. Proficiency in ship grid insulation reduction and single-phase ground faults. Skilled in the safe operation management of the main switchboard. Skilled in handling generator main switch trip failure under various conditions. Proficiency in the functional test of emergency switchboards and emergency generators. Proficiency points to the actual position of each component in the control box (according to the wiring diagram). Proficiency in judging the nature of the fault and the possible faults (according to the fault phenomenon).

\section{TEACHING DESIGN OF MARINE ELECTRICAL}

The core of the vessel electrical classroom teaching design is the design of "Training of seamen2016 as the standard", which highly integrates the three links of teaching, learning and evaluation. The reality is that the students learn what the teacher teaches and the teacher teaches that the interaction is diverse. What students learn is what they say." Based on the International Maritime Organization, national professional, industry standard teaching standards, the preparation of the teacher's curriculum plan, based on the teacher-based curriculum plan, design classroom teaching plan. Standardbased classroom teaching design does not require teachers to standardize teaching, nor is it a simple correspondence between classroom teaching content and professional teaching standards. It is that teaching objectives are derived from curriculum teaching standards, classroom teaching evaluation design precedes teaching process design, and reflects teaching standards. Consistency in classroom teaching and effect evaluation

According to the professional training objectives and curriculum standards, the teaching objectives of the curriculum are set. Firstly, the teaching themes and teaching contents of the ship electrical course are clearly defined, and the current state of study preparation of the higher vocational students is shared. The task completion status of the network resources is 
checked during the teaching process, or during the course. The questioning method is carried out. According to the teaching theory and the maritime bureau crew test qualification outline, syllabus industry norms, combined with the training conditions and teaching conditions of higher vocational colleges, according to the teaching objectives to determine the teaching ideas planning, the existing teaching materials teaching content, choose the right The teaching methods and teaching modes, the maximum possible use of Internet technology and teaching media resources, improve teaching behavior according to student learning effects, change the teaching implementation strategy.

Firstly, the teaching theme and content of the course of marine electrical should be clarified, and the students' learning preparation status should be shared. During the teaching process, the task completion of network resources should be checked, or the way of questioning in class should be adopted. According to the teaching theory and the seafarer examination syllabus and teaching syllabus industry standards of the Maritime Bureau, combined with the training conditions and teaching conditions of Higher Vocational colleges, according to the teaching objectives to determine the planning of teaching ideas, to deal with the existing teaching materials and teaching content, to choose the appropriate teaching methods and teaching mode, the maximum possible use of the Internet Technology and teaching media resources, according to the learning effect of students to improve teaching behavior, change the implementation of teaching strategies. Pre-class evaluation includes technical evaluation (reasonable situation, reasonable design), content evaluation (prominent, clear thinking, rich content).

Class evaluation includes teaching method evaluation (accurate language, encourage participation, pay attention to questions, timely feedback), learning method evaluation (reasonable method, coach combination, good at expression, good at thinking), activity evaluation (complete content, harmonious atmosphere, strong enthusiasm, high initiative).

After-class evaluation includes knowledge and skills (mastering key points, breaking through difficulties, acquiring skills), process methods (emphasizing process, emphasizing method, summarizing and sorting), emotional attitude (paying attention to experience, stimulating interest scientifically and rationally.As shown in Figure 1.

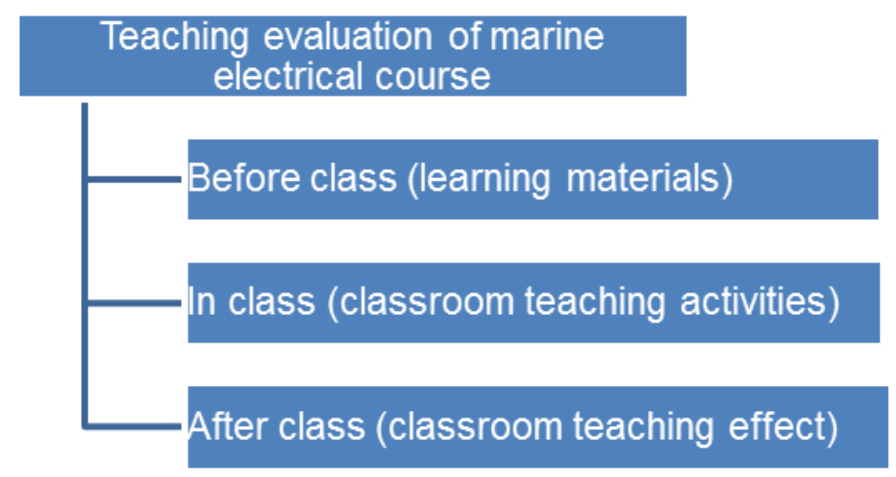

Fig. 1 Teaching evaluation of marine electrical course

\section{CONCLUSIONS}

The construction of marine electrical courses reflects the "four integrations", that is, the integration of professional settings and industrial needs, the integration of curriculum content and professional standards, the integration of teaching process and production process, and the integration of teaching theory and practice.

Deep learning is led by teachers. Students focus on challenging learning topics, actively participate, experience success, and develop a meaningful learning process. They also have critical understanding, organic integration, and constructive reflection.

The ship electrical course needs to be based on the new norms, new standards, combined with Internet + education, combined with the training conditions and teaching conditions of higher vocational colleges, determine the teaching ideas according to the teaching objectives, and handle the existing teaching materials. Teaching methods and teaching models. Taking students as the main body to develop the education reform of marine electrical courses, using the training requirements of crew members, adapting to the requirements of the development of the times, with research value, based on practical characteristics.

\section{REFERENCES}

[1] Li Zhenda. Application Research of Mobile Learning Based on "Internet + Education" in Secondary Vocational Information Technology Course[J]. Information and Computer (Theoretical Edition), 2018(13):250-251+254.

[2] Hong-jun MA. Research on the Influence of Badminton Microcurriculum Course Development and Teaching in Application-oriented Universities [A]. Advanced Science and Industry Research Center. Proceedings of 2018 International Conference on Education Reform and Management Science (ERMS2018)[C].Advanced Science and Industry Research Center: Science and Engineering Research Center,2018:4.

[3] Zhengyu Fan. Teaching Practice Research of Webpage Design and Making Course--Development of Mental Health Education Websites Based on Project Teaching[A]. Information Engineering Research Institute, USA, Singapore Management and Sports Science Institute, Singapore. Proceedings of 2018 5th ERMI International Conference on Social Issues, Social Work and Social Sciences (ERMI-SSS 2018)[C].Information Engineering Research Institute, USA, Singapore Management and Sports Science Institute, Singapore.

[4] Gang Chen. Research on Application of Micro-curriculum Design and Teaching Structure in Perspective of Lifelong Education[A]. Proceedings of 2016 5th International Conference on Social Science, Education and Humanities Research(SSEHR 2016)[C] (Computer Science and Electronic Technology International Society),2016:5.

[5] Yang hong. Transformation of Wisdom Curriculum Learning Methods and Micro-video Curriculum Design in Colleges and Universities Under the Background of Fragmented Learning[A]. Research Institute of Management Science and Industrial Engineering. Proceedings of 2017 2nd International Conference on Education, Sports, Arts and Management Engineering(ICESAME 2017)[C]. Research Institute of Management Science and Industrial Engineering: (Computer Science and Electronic Technology International Society),2017:5.

[6] Chen Juan. The Teaching Strategy of Junior Middle School Physics Review Course Based on "Deep Learning"_-Taking "Electrical Experiment Questions" Review as an Example[J].Science Volkswagen (Science Education), 2018(10):27-28. 